\title{
Differential expression and seasonal modulation of VGF peptides in sheep pituitary
}

\author{
Carla Brancia, Paola Nicolussi ${ }^{1}$, Pietro Cappai ${ }^{3}$, \\ Giorgio La Corte ${ }^{2}$, Roberta Possenti ${ }^{2}$ and Gian-Luca Ferri
}

\author{
NEF-Laboratory, Department of Cytomorphology, University of Cagliari, 09042 Monserrato, Cagliari, Italy \\ ${ }^{1}$ Istituto Zooprofilattico Sperimentale della Sardegna, Sassari, Sassari, Italy \\ ${ }^{2}$ Department of Neuroscience, 'Tor Vergata' University, Rome, Italy \\ ${ }^{3}$ Istituto Zootecnico Caseario della Sardegna, Bonassai, Sassari, Italy \\ (Requests for offprints should be addressed to G-L Ferri; Email: ferri@unica.it)
}

\begin{abstract}
The inducible gene $v g f$ and its peptide products are relevant to the neuroendocrine regulation of homeostasis and reproduction in rodents. We show here that in the anterior pituitary of female sheep the somatotrope, gonadotrope, and lactotrope/thyrotrope cell populations each expressed $v g f$ mRNA, but displayed a distinct profile of VGF immunoreactive peptides. ProVGF C-terminus and $\mathrm{VGF}_{443-588}$ immunoreactivities were found in lactotropes and thyrotropes, often in a subcellular location restricted to the Golgi area and suggestive of rapid peptide (or proVGF) release upon biosynthesis, while high molecular weight bands consistent with proVGF were shown in pituitary extracts. Distinct seasonal changes were revealed, proVGF C-terminus immunoreactive cells being largely identified as lactotropes during the summer $(83 \cdot 7 \pm 2 \cdot 1 \%$ (mean \pm S.E.M.) versus $27 \cdot 0 \pm 1 \cdot 9 \%$ during the winter), as opposed to thyrotropes during the winter
\end{abstract}

(73.0 $\pm 1 \cdot 9 \%$ versus $16 \cdot 3 \pm 2 \cdot 1 \%$ during the summer). Conversely, antisera to peptides adjacent to the $\mathrm{VGF}_{553-555}$ 'Arg-Pro-Arg' cleavage site, and to the N-terminus of the proVGF-derived peptide V, selectively labeled gonadotropes, indicating processing to small peptides not retaining the proVGF C-terminus in such cells. Finally, a peptide related to the $\mathrm{VGF}_{4-240}$ region was immunostained in somatotropes, shown in a Western blot as a band of relative molecular mass of approximately 16000 . In conclusion, a complex, endocrine cell-typespecific processing of proVGF was revealed. Further to the known inducibility of $v g f$ mRNA upon a range of stimuli, discreet, selective modulations of VGF-peptide profile/s are suggested, possibly involved in specific neuro/ endocrine or modulatory mechanisms.

Journal of Endocrinology (2005) 186, 97-107

\section{Introduction}

The vof gene (non-acronymic denomination) was discovered in PC12 rat pheochromocytoma cells because of its specific, 'delayed early' response to nerve growth factor (NGF) occurring at a later stage compared with immediate-early genes (Levi et al. 1985, Salton et al. 2000). In vivo, brain derived neurotropic factor (BDNF) was also shown to modulate vgf gene expression (Salton et al. 2000, Alder et al. 2003). The relevant gene product is the proVGF polypeptide, or VGF protein, composed of 617 or 615 amino acids (in rat/mouse and in man respectively, with over 85\% identity; Canu et al. 1997, Salton et al. 2000) and migrating as an approximately 90000 relative molecular mass band in Western blots. Ten stretches of paired basic amino acid residues are conserved across the rat, mouse and human coding sequences (Salton et al. 2000) and represent potential cleavage sites.
Processing of proVGF to intermediate and small molecular weight products has been shown in vivo (Possenti et al. 1989, Trani et al. 1995, 2002), and an endogenous peptide corresponding to the C-terminal 30 amino acid segment of human proVGF has been identified from bovine posterior pituitary (peptide V; Liu et al. 1994). Peptides derived from the proVGF C-terminal region were shown to be preferentially released in response to secretory stimuli from PC12 cells (Possenti et al. 1989), cerebellar granule cells (Trani et al. 1995), and insulinoma INS-1 cells (Possenti et al. 1999). In addition, processing at the $\mathrm{VGF}_{553-555}$ 'Arg-Pro-Arg' cleavage site has been shown, the resulting peptides displaying a TLQPP (Thr-Leu-Gln-Pro-Pro) sequence at their N-terminus (Trani et al. 2002).

In animal tissues, VGF immunoreactivity was found to be restricted to central and peripheral neurons (Van den Pol et al. 1989, 1994, Ferri et al. 1992), as well as endocrine cells of pituitary, adrenal medulla, gut and pancreas 
(Ferri et al. 1992, 1995, Possenti et al. 1999). Distinct vof gene induction was demonstrated in several models, such as in the mouse hypothalamic arcuate nucleus in response to fasting (Hahm et al. 2002), and in the suprachiasmatic nucleus in connection with light stimulation (Wisor \& Takahashi 1997). In the female rat anterior pituitary, VGF immunoreactivity was apparently restricted to gonadotropes and lactotropes, with striking VGF peptide/s degranulation at estrus in association with an increase in $v g f$ mRNA (Ferri et al. 1995). Deletion of the mouse VGF gene (knock-out) resulted in thin, small, hypermetabolic, hyperactive and relatively infertile animals (Hahm et al. 1999). VGF-deficient mice showed derangement of the hypothalamic outflow pathways that regulate peripheral metabolic tissues and energy homeostasis (Hahm et al. 2002), while the relevance of pituitary changes in connection with the observed reproductive alterations remains to be clarified (Hahm et al. 1999). Most recently, C-terminal proVGF-derived peptides were shown to induce penile erection upon injection into the rat paraventricular nucleus (Succu et al.2004). On the whole, a potential role has been proposed for proVGF-derived peptide/s as modulators in neuroendocrine secretory mechanisms, and/or as released neuro/endocrine messengers themselves (Salton et al. 2000).

In view of the striking modulation of $v g f$ mRNA and VGF peptides in rat pituitary over the estrous cycle (see above; Ferri et al. 1995), we decided to investigate the sheep pituitary in connection with the seasonal pituitary changes occurring in such seasonal breeding species. Since localization and modulation studies have so far been largely limited to peptides containing the C-terminal portion of proVGF, we developed and applied antisera to a range of further peptide stretches, mainly in connection with proVGF processing sites.

\section{Materials and Methods}

\section{Animals and tissue samples}

Samples were taken shortly post-mortem from female sheep of the Sardinian breed (aged 5-7 years, all groups) slaughtered for meat at a local abattoir during JanuaryFebruary $(n=7)$, June-July $(n=10)$, and October $(n=5)$. Hypophyses were divided into antero-posterior, vertical slices $(2-3 \mathrm{~mm}$ thick), immersion fixed in paraformaldehyde $\left(40 \mathrm{~g} / 1\right.$ in $0 \cdot 1 \mathrm{~mol} / 1 \mathrm{PO}_{4}$ buffer, $\mathrm{pH} 7 \cdot 2,0-4{ }^{\circ} \mathrm{C}$ for $3 \mathrm{~h}$ ), then washed in phosphate buffered saline (PBS: $10 \mathrm{~mol} / 1 \mathrm{PO}_{4}, \mathrm{pH} 7 \cdot 2-7 \cdot 4,150 \mathrm{mmol} / \mathrm{l} \mathrm{NaCl}$ ) containing sucrose $(200 \mathrm{mmol} / \mathrm{l})$ and $\mathrm{NaN}_{3}(3 \mathrm{mmol} / \mathrm{l})$. Slices were oriented in aluminum foil moulds (one each, sectioned surface down) in embedding medium (PBS containing $65 \mathrm{~g} / 1$ polyvinyl alcohol 56-98, $10 \mathrm{~g} / 1$ Tween-20, $40 \mathrm{~g} / 1$ polyethylene glycol 400, $15 \mathrm{mmol} / 1 \mathrm{NaN}_{3}$; Cocco et al. 2003) and snap-frozen in melting freon, cooled with liquid nitrogen. Cryosections (at a 5-6 $\mu \mathrm{m}$ setting) were obtained using a Microm HM-560 cold-blade cryomicrotome (Microm, Walldorf, Germany), and were collected on slides coated with either poly-L-lysine (relative molecular mass $>500$ 000, $1 \mathrm{~g} / \mathrm{l}$, in distilled water; Sigma, Milan, Italy) for immunocytochemistry, or 3-aminopropyltriethoxysilane (90 mmol/1, in acetone; Sigma) for in situ hybridization, air dried $(1-8 \mathrm{~h})$, wrapped in aluminum foil and stored in the vapor phase of a liquid nitrogen tank until used.

For Western blot, one of the above pituitary slices (roughly 25-30\% of the gland) was taken from each of 6 sheep (January-February, $n=3$; July, $n=3$ ) and chopped with a scalpel. Tissue was dropped into a pre-heated tube containing distilled water (approximately $10 \mathrm{ml} / \mathrm{g}$ tissue), kept in a vigorosly boiling water bath for $15 \mathrm{~min}$, and stored frozen. Upon addition of phenylmethylsulfonyl fluoride ( $5 \mathrm{mmol} / 1$ final concentration; Sigma), extracts were homogenized and briefly centrifuged $(3000 \mathrm{~g})$. Supernatants were heated in a boiling water bath (15 min), spun $(12000 \mathrm{~g}, 15 \mathrm{~min})$, decanted and stored at $-20{ }^{\circ} \mathrm{C}$ overnight upon addition of 6 volumes of an ethanol/ methanol/acetone mixture (2/1/1 proportions, $v / v)$. After centrifugation $(12000 \mathrm{~g}, 30 \mathrm{~min})$, pellets were dissolved using $4 \mathrm{~mol} / 1$ urea in $35 \mathrm{mmol} / 1$ sodium dodecyl sulfate (SDS). Total proteins were determined using a BCA protein assay reagent kit (Pierce, Rockford, IL, USA).

\section{Antisera}

VGF antisera were raised against (i) the rat and human proVGF C-terminus, (ii) two internally cleaved VGF peptides, sequenced from bovine and rat tissues respectively (Liu et al. 1994, Trani et al. 2002) and (iii) three VGF-beta-galactosidase fusion proteins encompassing longer domains within the rat proVGF. The topography of such antigens within the proVGF precursor is shown in Fig. 1, while all antisera and antibodies used are listed in Table 1.

In the C-terminal region of proVGF, a single amino acid substitution is found at position -3 (from C-terminus; Fig. 1), with an arginine $\left(\operatorname{Arg}_{613}\right)$ in man, as opposed to a histidine (His ${ }_{615}$ ) in rat and mouse (Salton et al. 2000). The relevant rat and human nonapeptides were synthesized (Affiniti-Biomol, Exeter, Devon, UK) and conjugated to bovine thyroglobulin via an additional N-terminal D-tyrosine for immunizations. The human VGF $_{586-595}$ sequence corresponds to the N-terminal part of bovine peptide $\mathrm{V}$ (Liu et al. 1994), while the rat $\mathrm{VGF}_{556-565}$ peptide corresponds to the N-terminal portion of VGF fragment/s found in rat brain (Trani et al. 2002). For both such peptides, at least the N-terminal five amino acids are identical in the corresponding regions of human and rat proVGF. The relevant peptides were synthesized (Affiniti-Biomol), and conjugated to keyhole limpet hemocyanin (KLH) via an additional C-terminal cysteine, to expose their $\mathrm{N}$-terminal region during immunizations. A fusion protein composed of a small, 21-amino acid 

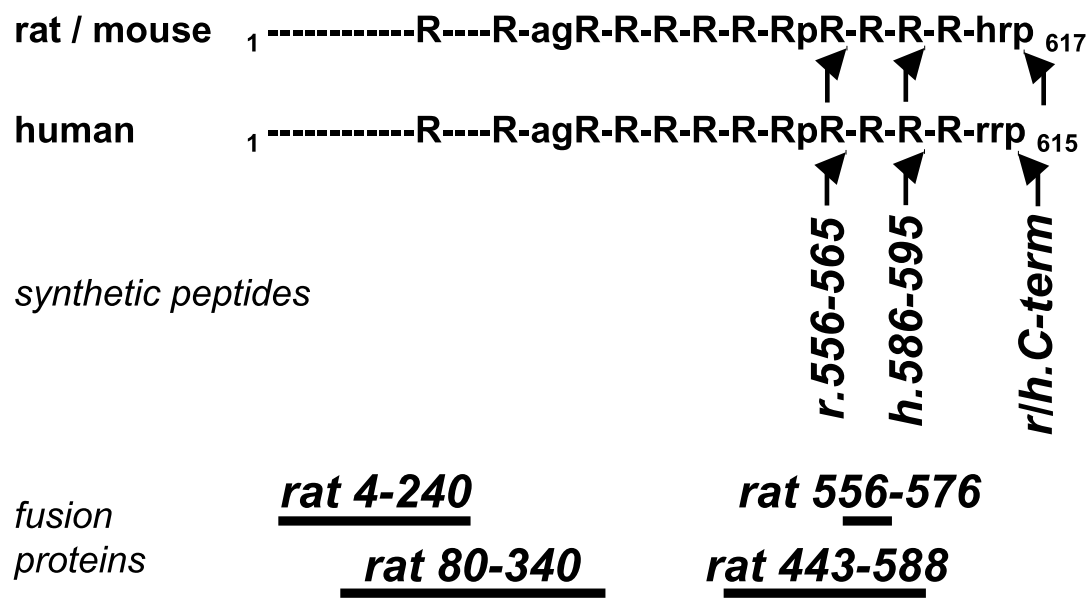

Figure 1 VGF peptides and fusion proteins used to raise antisera. Putative and confirmed processing sites within rat/mouse and human proVGF are indicated as $\mathrm{R}$ ( 2 or more $\mathrm{Arg} / \mathrm{Lys}$ basic residues), RpR (rat $\mathrm{Arg}_{553}-\mathrm{PrO}_{554}-\mathrm{Arg}_{555}$ processing site; Trani et al. 2002), or agR (putative processing-amidation site: rat $\mathrm{Ala}_{309}-\mathrm{Gly}_{310}-\mathrm{Arg}_{311}-\mathrm{Arg}_{312}$ ); the last 3

C-terminal amino acids are indicated in single-letter notation. Synthetic peptide antigens were conjugated (i) via N-terminal D-tyrosine to yield exposed C-termini, or (ii) via $\mathrm{C}$-terminal cysteine to expose their $\mathrm{N}$-termini during immunization (arrowheads are bent according to expected antiserum reactivity). r.556-565, rat $\mathrm{VGF}_{556-565}$; h.586-595, human VGF $_{586-595} ; \mathrm{r} / \mathrm{h}$.C-term, rat and human proVGF C-terminus.

VGF peptide (rat $\mathrm{VGF}_{556-576}$, also named TLQP-21), plus glutathione S-transferase (GST, from Schistosoma japonicum species), was obtained using the pGEX-4T-3 plasmid vector (Amersham Pharmacia, Milan, Italy) and used for guinea-pig immunizations. The VGF-betagalactosidase fusion protein antisera (against rat $\mathrm{VGF}_{4-240}$, rat $\mathrm{VGF}_{80-340}$ and rat $\mathrm{VGF}_{443-588}$ ) have been described previously in detail (Possenti et al. 1989, Ferri et al. 1992).

The hormone antisera and antibodies used (Table 1) showed negligible $(<0 \cdot 5 \%)$ cross-reactivity with other pituitary hormones or subunits in RIA, and resulted in consistent tissue labeling when compared in double/triple

Table 1 Antisera and antibodies used in the study

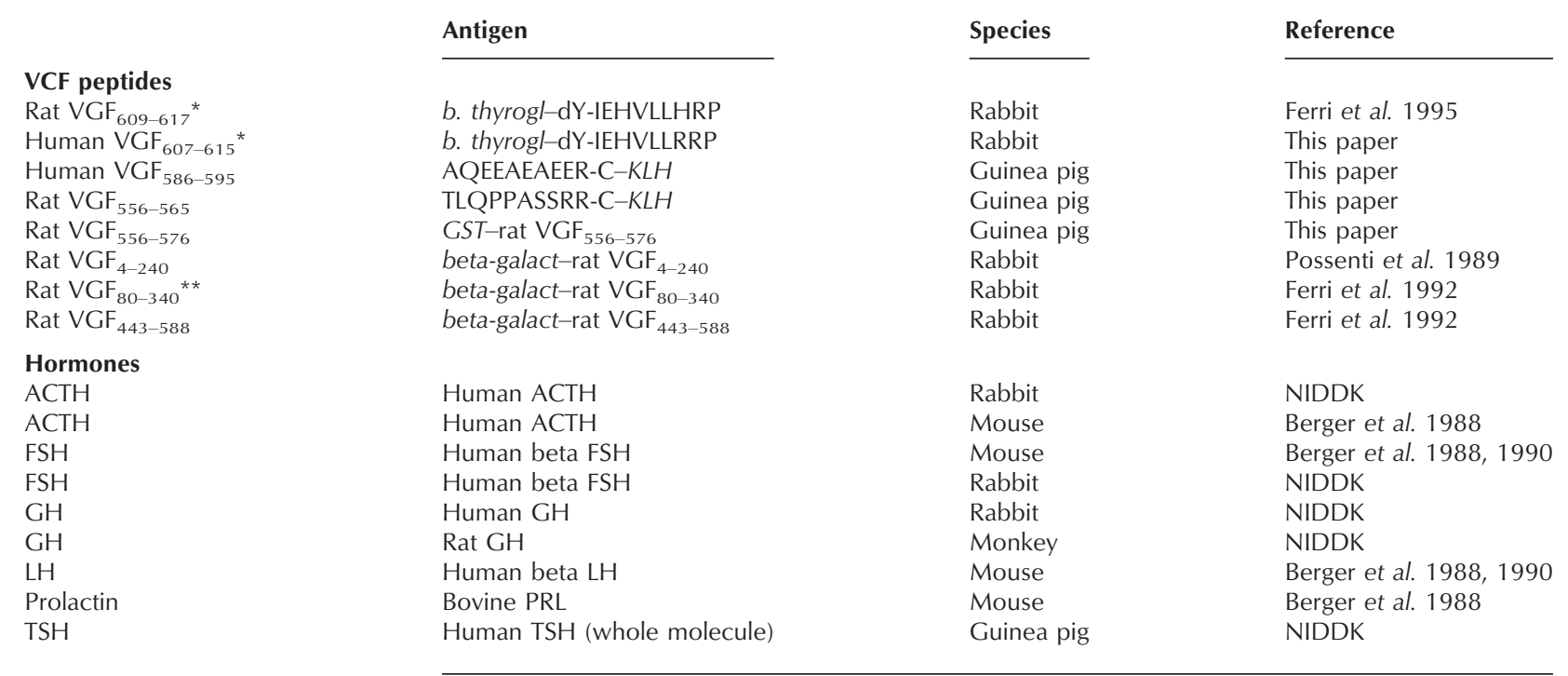

b. thyrogl, bovine thyroglobulin; beta-galact, beta-galactosidase; $K L H$, keyhole lympet haemocyanin; GST, glutathione-S-transferase; amino acids in single-letter notation, $\mathrm{dY}=\mathrm{d}$-tyrosine; $\mathrm{ACTH}$, adrenocorticotropin; ${ }^{*}$ rat/human proVGF C-terminus; ${ }^{* *}$ mainly used for Western blot. 
immunofluorescence, with no undue co-localization within the different pituitary cell types. Regarding gonadotropes, double labeling with luteinizing hormone (LH) and follicle-stimulating hormone (FSH) antisera/ antibodies resulted in 65-70\% double-labeled cells, fewer cells being only LH (about 20-25\%) or only FSH immunoreactive (10-12\%). Since the thyrotropin (TSH) antiserum was raised against whole TSH, it could contain alpha subunit antibodies, thus potentially also labeling gonadotropes. Such antiserum was revealed with the AMCA fluorochrome staining (blue, see below) and compared with a mixture of anti-beta-LH and anti-betaFSH mouse antibodies (both revealed in green). Any pituitary cell labeled by the anti-LH/FSH mixture (green) was identified as a gonadotrope (whether or not it was also labeled with AMCA, i.e. blue), while blue-only cells were assumed to be thyrotropes.

\section{Immunohistochemistry and labeled cell quantitation}

Sections were soaked in Triton X-100 $\left(0 \cdot 1 \%\right.$ in $\mathrm{H}_{2} \mathrm{O}$ for $1 \mathrm{~h}$; Merck, Milan, Italy), incubated overnight with antiVGF antiserum/a (at room temperature), then with cyanine 3.18 (Cy3)-conjugated anti-guinea pig or antirabbit antibody, as relevant $(1 \mathrm{~h})$. All VGF antisera effectively immunostained the endocrine cells in sheep pituitary, except for the $\mathrm{VGF}_{80-340}$ antiserum, which resulted in weak labeling and was thus mainly used in Western blot. Antisera raised against comparatively short peptide stretches (rat $\mathrm{VGF}_{556-565}$ and human $\mathrm{VGF}_{586-595}$, as well as the fusion protein encompassing rat $\mathrm{VGF}_{556-576}$ ) appeared to react preferentially with the relevant, cleaved peptides (see below). In a few additional experiments we used far higher than usual concentrations of such antisera (up to tenfold) in order to test their reactivity with the proVGF precursor.

Endocrine cell populations were characterized on the basis of their hormonal content/s by double and triple immunofluorescence, including one or two anti-pituitary hormone antisera/antibodies in the primary incubation step. Secondary antibodies used (from donkey; Jackson ImmunoResearch Laboratories, West Grove, PA, USA) were conjugated with one of the following: (i) cyanine $3 \cdot 18$ (Cy3, emitting in yellow-red), (ii) 7-amino-4methylcoumarin-3-acetic acid (AMCA, blue), (iii) either cyanine 2.18 (Cy2, green) or biotin, followed by Alexa 488-labeled avidin (green; Molecular Probes, Leiden, The Netherlands). All antisera and antibodies were diluted in PBS containing normal donkey and sheep sera (3\% each), while conjugated avidin was dissolved in PBS containing $10 \mathrm{~g} / 1$ bovine serum albumin. Absorption controls were carried out using the relevant peptides and fusion proteins (up to $50 \mathrm{nmol} / \mathrm{ml}$ ), the homologous peptide resulting in virtual prevention of immunostaining, while unrelated peptides and carrier protein had no significant effect. Routine controls included substitution of each primary antiserum, in turn, with non-immune serum or PBS. Preparations were observed using an Olympus BX60 fluorescence microscope equipped with a PM30 photographic system (Olympus, Milan, Italy) and a Fuji FinePix S2 PRO digital camera (Fujifilm, Milan, Italy).

As described below (see Results section), three patterns of immunolocalization were shown with the antisera to (i) C-terminus and $\mathrm{VGF}_{443-588}$, (ii) $\mathrm{VGF}_{556-565}, \mathrm{VGF}_{556-576}$ and $\mathrm{VGF}_{586-595}$, and (iii) $\mathrm{VGF}_{4-240}$. Hence, the Cterminus, $\mathrm{VGF}_{556-565}$, and $\mathrm{VGF}_{4-240}$ antisera were used for quantitation, which was carried out on preparations double/triple immunostained for VGF and the relevant pituitary hormone/s. Pilot experiments were subjectively assessed by two independent observers in a blind fashion, and revealed distinct differences between summer and winter specimens with the C-terminus and $\mathrm{VGF}_{443-588}$ antisera, but not with the others. Quantitation was then carried out by a single observer, with labeled cells showing a visible (unlabeled) nuclear profile being counted on 3 non-adjacent sections each from either 13 sheep pituitaries for the C-terminus antiserum (summer and winter, $n=5$ each; autumn, $n=3$ ), or 4 sheep pituitaries for the $\mathrm{VGF}_{4-240}$ and $\mathrm{VGF}_{556-565}$ antisera (summer and winter, $n=2$ each). Data were expressed as means \pm S.E.M. throughout. Statistical analysis was carried out by one-way ANOVA, followed by post-hoc multiple comparison tests (StatistiXL software, www.statistXL.com).

\section{In situ hybridization}

An approximately $600 \mathrm{bp}$ fragment of rat VGF cDNA (BamHI-XhoI 235-854 bp from the ATG of the coding sequence) was cloned in both orientations, downstream of the T7 polymerase promoter. Labeled antisense and sense probes were obtained by in vitro transcription of the linearized plasmids with T7 polymerase, using Megascript labeling kits (Ambion, Austin, TX, USA) and digoxigenin-11-UTP (Roche, Monza, Italy). The hybridization buffer contained $50 \%$ deionized formamide, $1 \%$ blocking solution (Roche), $5 \mathrm{mmol} / 1 \mathrm{EDTA}, 5 \times \mathrm{SSC}$, $0 \cdot 1 \%$ Chaps (Sigma), $0.1 \mathrm{mg} / \mathrm{ml}$ heparin (Sigma), $1 \mathrm{mg} / \mathrm{ml}$ yeast total RNA, and $10 \mathrm{mg} / \mathrm{ml}$ denatured sheared herring sperm DNA (reagents from either Roche or Sigma, as relevant; see Moorman et al. 2001).

Sections were treated with Triton X-100 $(0 \cdot 1 \%$ in PBS), then digested with proteinase $\mathrm{K}(1 \mu \mathrm{g} / \mathrm{ml}$, in PBS containing $1 \mathrm{mmol} / 1 \mathrm{EDTA}$, for $20 \mathrm{~min}$; ICN, Milan, Italy) followed by treatment with glycine $(25 \mathrm{mmol} / \mathrm{l}$, in PBS for $5 \mathrm{~min}$ ) and post-fixation with paraformaldehyde (4\% in PBS for $5 \mathrm{~min}$ ). After a pre-incubation step with hybridization buffer (at $70{ }^{\circ} \mathrm{C}$ for $1 \mathrm{~h}$ ), preparations were hybridized overnight with the relevant probe dissolved in hybridization buffer (at $70^{\circ} \mathrm{C}$ ). After RNase digestion $\left(100 \mu \mathrm{g} / \mathrm{ml}\right.$; from ICN) and stringency washes $\left(\right.$ at $70{ }^{\circ} \mathrm{C}$; $2 \times \mathrm{SSC}, 2 \times 10 \mathrm{~min} ; 1 \times \mathrm{SSC}, 0 \cdot 5 \times \mathrm{SSC}, 0 \cdot 25 \times \mathrm{SSC}$, $10 \mathrm{~min}$ each; $1 \times \mathrm{SSC}=150 \mathrm{mmol} / 1 \mathrm{NaCl}, 15 \mathrm{mmol} / 1$ 
sodium citrate, $\mathrm{pH} 7 \cdot 2$ ), the bound probe was revealed using alkaline phosphatase-labeled anti-digoxigenin Fab fragment antibodies (Roche) diluted in AP1 buffer $(1 \mathrm{~mol} / 1$ Tris- $\mathrm{HCl}, \mathrm{pH} 7 \cdot 6$, containing $5 \mathrm{~mol} / 1 \mathrm{NaCl}$, $0.5 \mathrm{~mol} / 1 \mathrm{MgCl}_{2}$ and $30 \mathrm{~g} / 1$ bovine serum albumin). Overnight development was carried out using a 5-bromo4-chloro-3-indolyl phosphate/nitroblue tetrazolium kit, with inclusion of levamisole, according to the kit's instructions (Vector, Burlingame, CA, USA). Controls included incubation with sense probe, probe omission, as well as pre-digestion of sections with RNase $\left(100 \mu \mathrm{g} / \mathrm{ml}, 37^{\circ} \mathrm{C}\right.$ for $1 \mathrm{~h}$ ). Preparations were observed as described for immunohistochemistry.

\section{Western blot}

Extracted proteins (approximately $20 \mu \mathrm{g}$ ) were loaded onto gels, and NuPAGE 10\% bis/tris gels were run and blotted with XCell SureLock, according to the procedure's protocol (NuPAGE System, Invitrogen, San Giuliano Milanese, Italy). The relevant peptides and fusion proteins were effectively used for preabsorption controls with each of the VGF antisera (up to about $50 \mathrm{nmol} / \mathrm{ml}$ ). In view of the limited retention of low molecular weight peptides in Western blot, pilot runs were carried out loading rat $\mathrm{VGF}_{556-576}$ (21 amino acid, or TLQP-21), or synthetic rat VGF $586-617$ (30 amino acid rat sequence, corresponding to bovine peptide $\mathrm{V}$; Affiniti-Biomol). As expected, such small peptides were scarcely retained and resulted in no detectable signal with the relevant antisera. On this basis, and in view of the immunocytochemical findings, use of the $\mathrm{VGF}_{556-565}$, $\mathrm{VGF}_{556-576}$ and $\mathrm{VGF}_{586-595}$ antisera in $\mathrm{Western}_{\text {blot was }}$ not pursued further.

\section{Results}

Using the various VGF antisera, endocrine cells were labeled in varied numbers and intensities in female sheep anterior pituitary. The rat C-terminus (rat $\mathrm{VGF}_{609-617}$ ) antiserum resulted in sparse labeling, while the one raised against the corresponding human sequence (human $\mathrm{VGF}_{607-615}$ ) showed reproducible, bright immunostaining and was henceforth used. When the distribution of VGF immunoreactivity was studied systematically, three main differential patterns became apparent (Fig. 2A-C). The human proVGF C-terminus $\left(\mathrm{VGF}_{607-615}\right.$, Fig. $\left.2 \mathrm{~A}\right)$ and $\mathrm{VGF}_{443-588}$ antisera mainly decorated strands of pituitary endocrine cells, often distinctly granular in appearance. At close inspection, many such cells showed a sharply localized area of intracellular labeling, close to the cell nucleus and identified as the bona fide Golgi area (Fig. 2A, insert). Conversely, antisera raised against sequences adjacent to the $\mathrm{VGF}_{553-555}$ 'Arg-Pro-Arg' internal cleavage site (rat $\mathrm{VGF}_{556-565}$, Fig. $2 \mathrm{~B}$, and rat $\mathrm{VGF}_{556-576}$ antisera), and to the N-terminus of peptide $\mathrm{V}$ (anti-human $\mathrm{VGF}_{586-595}$ ) revealed numerous, singly distributed endocrine cells of medium size and with moderate to bright intensity. Finally, immunoreactivity for the $\mathrm{VGF}_{4-240}$ fusion protein was largely found in scattered groups and clusters of cells, of fairly consistent labeling intensity (Fig. 2C).

In double and triple immunolabeling experiments, the above patterns were linked to specific endocrine cell populations. Labeling with the proVGF C-terminus $\left(\mathrm{VGF}_{607-615}\right)$ and $\mathrm{VGF}_{443-588}$ antisera was co-localized with prolactin and/or TSH (Fig. 3A-H), but not with the other hormones tested. When samples taken at different times over the year were compared, proVGF C-terminus immunoreactive cells were largely identified as lactotropes during the summer, with the addition of a fraction of thyrotropes, while an almost reverse pattern was found in winter (Fig. 4, upper panel). Most of such changes could be accounted for by an increase in VGF peptideexpressing lactotropes during summer and autumn (40-50\%, as opposed to about 15\% during winter; Fig. 4, lower panel), while the proportion of proVGF C-terminus immunoreactive thyrotropes showed a less evident increase from summer and autumn to winter (Fig. 4, lower panel). Conversely, cleavage-site-related peptides $\left(\mathrm{VGF}_{556-565}, \mathrm{VGF}_{586-595}\right.$ and $\mathrm{VGF}_{556-576}$ antisera) were detected in most gonadotropes, co-localized with LH (Fig. 2D,E, Fig. 4, lower panel) and/or FSH, but not in other pituitary endocrine cell types. Finally, $\mathrm{VGF}_{4-240}$ peptide immunoreactivity was revealed in the vast majority of somatotropes (Fig. 2F,G, Fig. 4, lower panel), and in a small fraction of corticotropes (3-5\%: not shown), but did not colocalize with LH/FSH, prolactin or TSH. No distinct seasonal changes were revealed for $\mathrm{VGF}_{556-565}, \mathrm{VGF}_{556-576}, \mathrm{VGF}_{586-595}$, or $\mathrm{VGF}_{4-240}$ immunoreactivity.

As mentioned, absorption controls confirmed specificity of the immunostaining obtained with the various VGF antisera. Antisera generated against peptides adjacent to proVGF cleavage sites (rat $\mathrm{VGF}_{556-565}$, rat $\mathrm{VGF}_{556-576}$ and human $\mathrm{VGF}_{586-595}$ ) were tested further. When these were used under standard conditions, i.e. at dilutions which reliably provided bright labeling and high signal-to-noise ratio, they all resulted in immunolabeling completely separate from that obtained with the other VGF antisera. Conversely, when the same antisera were applied at 5-10 times higher concentrations, co-labeling with the proVGF C-terminus antiserum was shown in many endocrine cells, suggestive of a low-key, concentration-dependent reactivity with the proVGF precursor (not shown).

In in situ hybridization experiments, $v g f$ mRNA was revealed in a large number of pituitary endocrine cells. When studied in parallel with the relevant VGF peptides by immunostaining of adjacent sections, $v g f$ mRNA was consistently revealed in most growth hormone $(\mathrm{GH})$ cells (Fig. 2 L,M). Labeling intensity for the same mRNA varied in VGF peptide immunoreactive gonadotropes, 


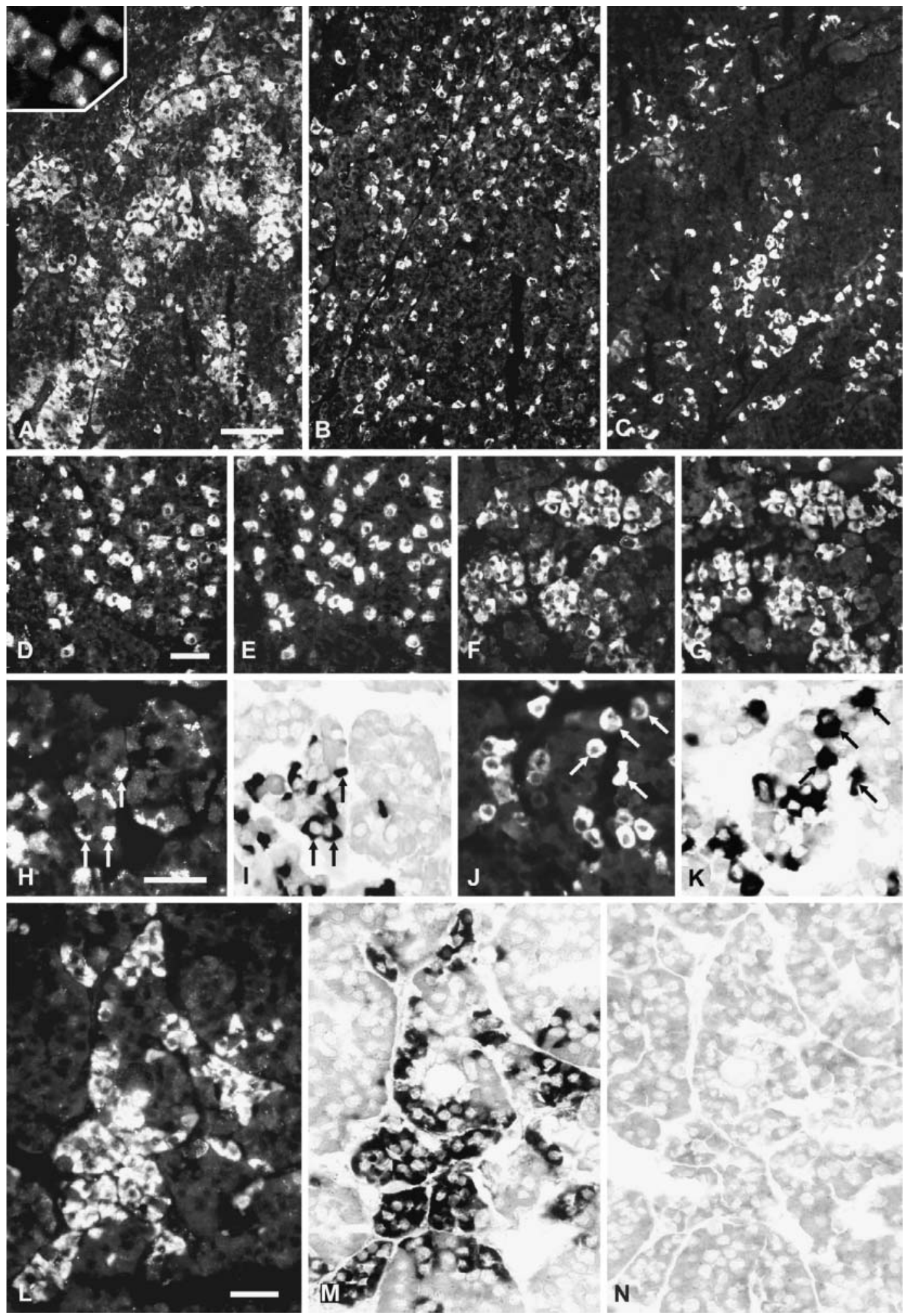


lactotropes and thyrotropes (Fig. 2H-K), each showing intensely labeled, faint and hardly labeled cells within the same pituitary, in virtually all animals. When possible seasonal changes were addressed, the large number of diverse $v g f$ mRNA-containing cells and their varied labeling extent made it hardly possible to reveal clear cut differences. RNase and sense probe preparations were devoid of localized signal (Fig. 2N).

In Western blot, the proVGF C-terminus $\left(\mathrm{VGF}_{607-615}\right)$ and $\mathrm{VGF}_{443-588}$ antisera mostly showed large forms of approximately 90000 relative molecular mass (Fig. 3I, lanes 1-4), in agreement with the expected migration of the human proVGF precursor. Only minor amounts of additional, low relative molecular mass bands down to approximately 20000 were revealed with the $\mathrm{VGF}_{443-588}$ antiserum (Fig. 3I, lanes 1,2). A single, approximately 16000 relative molecular mass band was revealed using the $\mathrm{VGF}_{4-240}$, or $\mathrm{VGF}_{80-340}$ antisera (Fig. 3I, lanes 5-8), with minor reactivity in the high molecular mass range corresponding to proVGF.

\section{Discussion}

On the basis of the present study, vgf mRNA and its derived peptide/s are well represented in sheep pituitary. In lactotropes and thyrotropes, proVGF precursor appeared to be the major intracellular product, as shown by the results obtained with proVGF C-terminus and $\mathrm{VGF}_{443-588}$ antibodies in both Western blot and immunohistochemistry. Striking seasonal changes were revealed, the vast majority of proVGF C-terminus (and $\mathrm{VGF}_{443-588}$ ) immunoreactive cells being identified as lactotropes during the summer, and as thyrotropes during the winter. Conversely, processing to smaller peptides appeared to occur in gonadotropes, as shown by labeling for peptides cleaved at the $\mathrm{VGF}_{553-555}$ 'Arg-Pro-Arg' site, as well as for the $\mathrm{N}$-terminus of peptide $\mathrm{V}$, while proVGF C-terminus antibodies were negative. A novel VGF peptide was shown in somatotropes, of approximately 16000 relative molecular mass in Western blots. In view of its reactivity with both $\mathrm{VGF}_{4-240}$ and $\mathrm{VGF}_{80-340}$ antisera, such a peptide band was probably related to the corresponding $\mathrm{VGF}_{80-240}$ overlap region. No apparent seasonal changes were revealed for VGF peptides contained in either gonadotropes, or somatotropes. Regarding corticotropes, a minor fraction $(3-5 \%)$ was labeled by $\mathrm{VGF}_{4-240}$ antibodies, while all other VGF antisera used were negative.

Thus, selective, differential VGF peptide profiles were displayed by the major hypophyseal endocrine cell types, with the virtual exception of corticotropes. The latter 'negative' finding, however, ought to be interpreted with caution, since several regions of proVGF have been little studied. In addition, a few further VGF-derived peptides have been identified, but would not be recognized by the antisera we used. These include proVGF N-terminus and $\mathrm{VGF}_{378-397}$-related peptides identified from the human cerebrospinal fluid (Stark et al. 2001, Carrette et al. 2003). Furthermore, the sheep vof gene has not yet been sequenced, hence its coding region might differ from the highly conserved sequence found in rat, mouse and human genes (Salton et al. 2000). At the proVGF C-terminus, a single amino acid substitution is shown at position -3 , an arginine (Arg 513) being found in human proVGF as opposed to a histidine (His ${ }_{515}$ ) in rat/mouse (Salton et al. 2000). The far better reactivity that we found with human $\mathrm{VGF}_{607-615}$ antibodies, as opposed to those raised against the corresponding rat $\mathrm{VGF}_{609-617}$ peptide, suggests that the sheep VGF precursor may be closely related to human proVGF in such a region. The latter observation is in keeping with the reported sequence of peptide $V$, which was isolated from the bovine pituitary and proved identical to the C-terminal 30 amino acid domain of human proVGF (Liu et al. 1994). In several rat neuroendocrine tissues, both $\mathrm{VGF}_{4-240}$ and $\mathrm{VGF}_{80-340}$ antisera revealed bands of relative molecular mass of approximately 90000 in Western blots, corresponding to proVGF (Possenti et al. 1989, Trani et al. 1995). As shown for the human gene (Salton et al. 2000), amino acid substitutions might be present in the comparatively $\mathrm{N}$-terminal portions of sheep proVGF compared with the rat sequence, and could explain the low reactivity of the above antisera with sheep proVGF.

Proteolytic precursor processing in neuroendocrine cells largely occurs in secretory granules, via endoproteases that act upon recognition of specific stretches of basic amino acid residues and their surrounding sequence/s. The best characterized prohormone processing enzymes acting on proVGF are PC1/3 and PC2 (Trani et al. 2002). These are expressed in endocrine and neuroendocrine cells, being

\footnotetext{
Figure 2 VGF immunohistochemistry and in situ hybridization. (A-C) The distinct differential localization shown using different VGF antisera. (A) The proVGF C-terminus antiserum $\left(V_{G F}{ }_{607-615}\right)$ revealed multiple strands of pituitary endocrine cells, often with a localized area of labeling identified as the bona fide Golgi region (insert). (B) Peptides adjacent to VGF cleavage sites (here VGF ( $56-565$ ) were brightly immunostained in single, scattered cells. (C) The VGF $V_{4-240}$ antiserum mainly decorated groups and clusters of endocrine cells. Consecutive sections, immunofluorescence with Cy3-labeling; scale bar $=100 \mu \mathrm{m}$, except for insert where the same bar $=30 \mu \mathrm{m}$. (D-G) Cleaved VGF peptide immunoreactivity was selectively localized in gonadotropes ( $D_{,}$VGF $_{586-595}$ antiserum, versus $E$, LH), while the $V_{G F}{ }_{4-240}$ antiserum (F) largely labeled somatotropes $(G, G H)$. Double immunofluorescence; scale bar $=30 \mu \mathrm{m}$. $(\mathrm{H}-\mathrm{N})$ vgf gene expression versus VGF peptides. vgf mRNA labeling intensity varied in VGF-immunoreactive lactotropes and thyrotropes $\left(\mathrm{H}, \mathrm{VGF}_{607-615}\right.$ antiserum versus I, vgf mRNA), or gonadotropes $\left(\mathrm{J}, \mathrm{VGF}_{556-565}\right.$, versus $\mathrm{K}$, vgf mRNA), while it was fairly consistent in somatotropes $\left(\mathrm{L}, \mathrm{VGF}_{4-240}\right.$, versus $M, v g f m R N A)$. N, sense-probe control. Adjacent serial sections, indirect immunofluorescence and in situ hybridization; scale bars $=20 \mu \mathrm{m}$.
} 

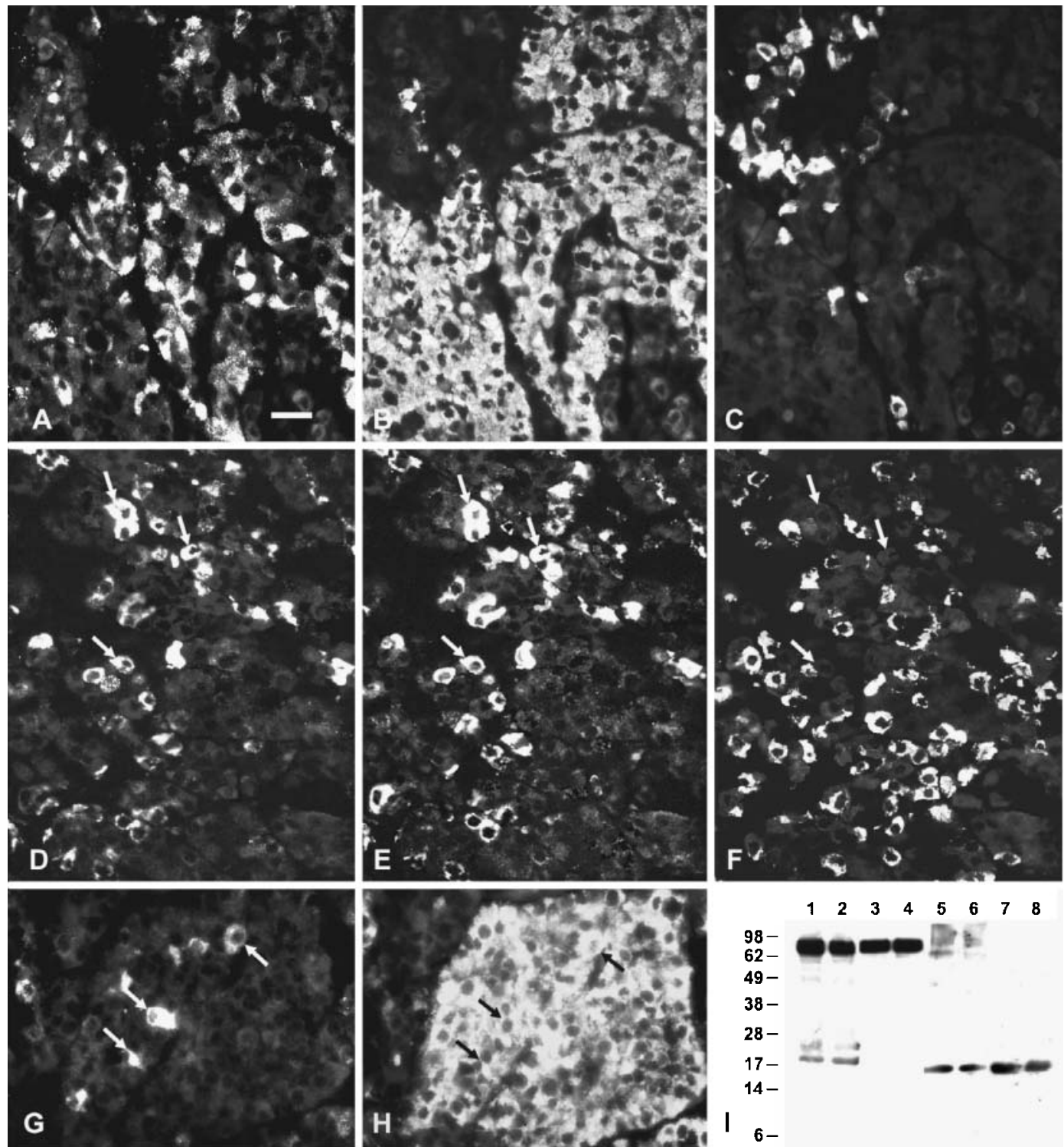

Figure 3 Seasonal changes in VGF localization and Western blots. (A-C) During the summer, proVGF C-terminus immunoreactive cells were mostly identified as lactotropes $\left(A, V_{G F} F_{607-615}\right.$, versus $B$, prolactin), while only a few were thyrotropes $\left(A, V_{G F} F_{607-615}\right.$, versus $\left.C, T S H\right)$. $(D-H)$ During the winter, the same VGF peptide/s were largely found in thyrotropes ( $\mathrm{D}, \mathrm{VGF}_{607-615}$, versus $\mathrm{E}, \mathrm{TSH} ; \mathrm{F}, \mathrm{LH}$, for comparison), with the addition of a small number of lactotropes (G, VGF $607-615$, versus $H$, prolactin). Triple/double immunofluorescence; scale bar $=30 \mu \mathrm{m}$. (I) In Western blot, $\mathrm{VGF}_{443-588}$ and C-terminus antisera (lanes 1, 2 and 3, 4 respectively) showed high molecular mass bands, compatible with the proVGF precursor, only minor amounts of low molecular mass forms were revealed by the former antiserum. $\mathrm{VGF}_{4-240}$ and $\mathrm{VGF}_{80-340}$ antisera (lanes 5, 6, and 7, 8 respectively) revealed an approximately 16000 relative molecular mass band, while scarcely reacting with proVGF. Extracts from two sheep pituitaries, taken during the summer (lanes 1, 3, 5, 7), and winter (lanes 2, 4, 6, 8) are shown.

especially abundant within the pituitary in corticotropes, gonadotropes and thyrotropes (Takumi et al. 1998). PC2 and PC1 convertases were localized to different secretory granules in rat gonadotropes (Uehara et al. 2001). Our findings suggest that sheep gonadotropes may be similarly provided with the latter convertases. In the rat, the secretory granule protein chromogranin A and its derived beta-granin and WE-14 peptide fluctuated in FSH- and LH-containing gonadotropes over the estrous cycle (McVicar et al. 2003), in keeping with the similar modulation we observed for C-terminus VGF immunoreactivity in the same species (Ferri et al. 1995). In addition 

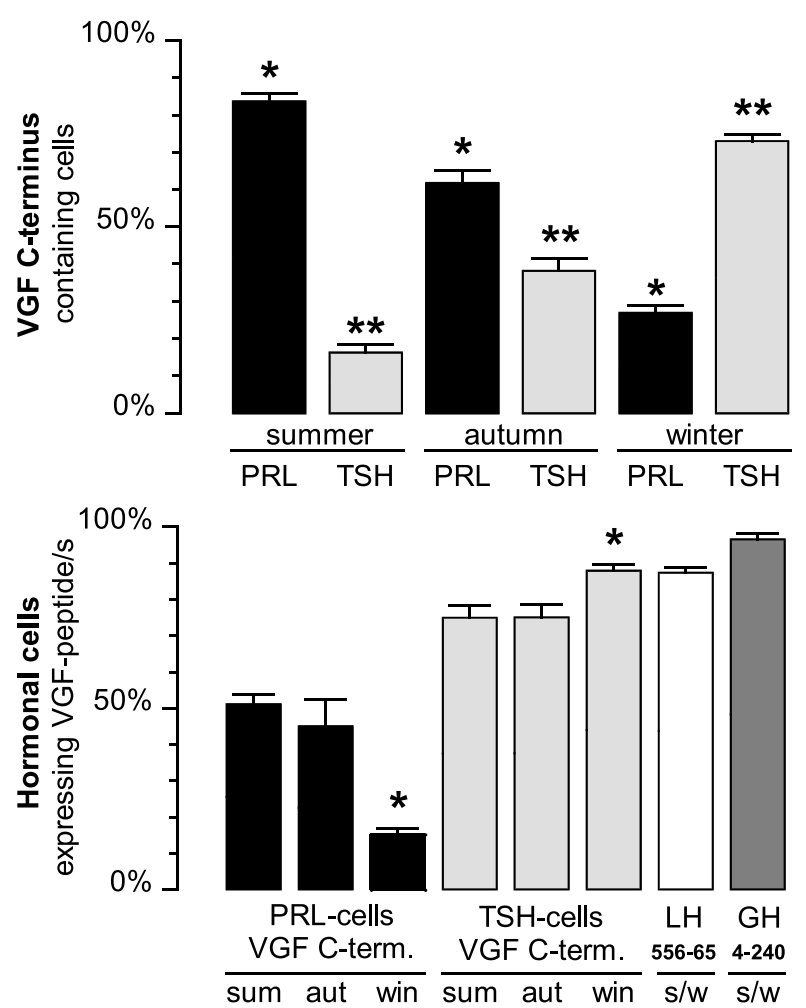

Figure 4 Quantitation of VGF immunoreactive cells. (Upper panel) Cells labeled by the proVGF C-terminus antiserum were mostly identified as lactotropes during the summer, as opposed to thyrotropes during the winter (PRL, lactotropes; $\mathrm{TSH}$, thyrotropes; ${ }^{*}$ or ${ }^{* *}=, P<0 \cdot 001$, summer versus autumn/winter, and autumn versus winter). (Lower panel) Expression of immunoreactive VGF peptides in the main pituitary endocrine cells types (PRL, lactotropes; $\mathrm{TSH}$; thyrotropes; $\mathrm{LH}$, gonadotropes; $\mathrm{GH}$, somatotropes; VGF C-term., 556-65, 4-240: VGF $607-615$, $\mathrm{VGF}_{556-565}$ and $\mathrm{VGF}_{4-240}$ immunoreactive peptides respectively; sum, summer; aut, autumn; win, winter; $\mathrm{s} / \mathrm{w}$, average summer and winter; ${ }^{\star} P<0 \cdot 05$, winter versus summer/autumn).

to pituitary gonadotropes, proVGF C-terminus antisera effectively revealed VGF cleaved peptides in various other rat tissues (Trani et al. 1995), and permitted the determination of proVGF processing by PC1/3 and PC2 convertases (Trani et al. 2002). In addition, processing was demonstrated at the $\operatorname{Arg}_{553}-\mathrm{PrO}_{554}-\mathrm{Arg}_{555}$ site (Trani et al. 2002), resulting in the production of peptide/s displaying a TLQPP sequence at their N-terminus. Our findings with TLQPP-related antisera $\left(\mathrm{VGF}_{556-565}\right.$ and $\mathrm{VGF}_{556-}$ 576), as well as with the antiserum to the N-terminus of bovine peptide $\mathrm{V}\left(\mathrm{VGF}_{586-595}\right.$; Liu et al. 1994) suggest that the relevant peptides are produced in sheep gonadotropes. Pending their precise identification, such TLQPPcontaining and peptide V-related peptides appear not to extend all the way to the proVGF C-terminus, although they could not be studied further by Western blot due to their comparatively small size.
The seasonal changes revealed for proVGF-related peptide/s across sheep lactotropes and thyrotropes may be related to the known seasonal modulation of prolactin, as well as of TSH and thyroid hormone secretion. In sheep, lactotrope cells are increasingly stimulated from winter to summer, serum prolactin being higher during long days (from spring to summer) and lower during short days (from autumn to winter; Pelletier 1973, Ravault 1976). In the same species, the pituitary pars tuberalis is probably involved in stimulating prolactin secretion (Graham et al. 2002), while prolactin may be involved in seasonal inhibition of gonadotropin release via a paracrine intrapituitary mechanism (Tortonese et al. 1998), probably also involving dopamine (Gregory et al. 2004). Conversely, thyrotropes can be stimulated in response to reduced ambient luminosity, in apparent connection with a higher need for heat production via increased thyroid hormone release during the winter months (Hassi et al. 2001). Thyroid hormones show seasonal modulation in sheep, and are necessary during an interval late in the breeding season to promote seasonal reproductive suppression (Thrun et al. 1997). In the present study, we used samples from slaughterhouse sheep of the Sardinian breed, which were of undetermined reproductive state they probably included cyclic as well as lactating animals, as seasonally appropriate. In sheep of the Sardinian breed, ovarian activity increases in connection with decreasing day length, with the highest sexual activity in adult animals occurring during November and the lowest in April (Manunta \& Casu 1968). Recent parturition, or the presence of males also affect cyclical activity (Cappai et al. 1984). Seasonal modulation of prolactin secretion has been confirmed in the Sardinian breed of sheep (Carcangiu et al. 1995), while TSH has been little studied.

Further to seasonal modulation, restriction of proVGF C-terminus (and $\mathrm{VGF}_{443-588}$ ) immunostaining to the Golgi area in many lactotropes may suggest stimulated biosynthesis and release of proVGF, and/or of other, as yet unknown, VGF peptide/s. A similar picture was shown in rat pituitary in the morning following the estrous peak secretion of LH, both in gonadotropes degranulated of their previous VGF content, as well as in lactotropes, in parallel with raised pituitary vgf mRNA levels (Ferri et al. 1995). It is conceivable that proVGF and/or certain of its product/s are involved in secretory mechanisms operating under conditions of enhanced stimulation, in which circumstances they undergo almost complete release from their cells of expression. Further to a possible involvment in hormonal release mechanisms, VGF peptides themselves could act as endocrine messengers, proVGF possibly representing a multifunctional precursor (Salton et al. 2000). Furthermore, paracrine roles ought to be considered for VGF peptides, as appears to be the case for certain pro-opiomelanocortin-derived and several other peptides (Denef \& van Bael 1998). 
In the rat, VGF is also well represented in several hypothalamic nuclei, including the suprachiasmatic, supraoptic, paraventricular and arcuate nuclei (Van den Pol et al. 1989, 1994). In the hamster suprachiasmatic nucleus, vof mRNA is induced by light in the caudal portion, with delayed kinetics, while showing circadian rhythmicity in the rostral portion (Wisor \& Takahashi 1997). While little is known of comparable VGF responses in farm animals, including sheep, the latter finding may be relevant to seasonal modulatory and reproductive mechanisms. A specific investigation of the sheep's pituitary pars tuberalis may also be of interest, in view of its involvment in seasonal rhythmicity (Lincoln et al. 2003). As to the regulation of VGF peptide/s expression, the $v g f$ gene was originally recognised due to its responsiveness to NGF in PC12 cells (Levi et al. 1985), hence it is relevant to note that both NGF and its receptors are found not only in many areas of the nervous system, but also in the pituitary (Patterson \& Childs 1994). In different tissues and species, however, vgf and its products may also respond to BDNF (Alder et al. 2003) and to a range of other factors (Salton et al. 2000).

In conclusion, proVGF appears to be widely expressed, but differentially processed, in most pituitary cell types. In vivo and in vitro release studies, as well as precise identification of VGF peptide products, will enable their testing for endocrine and/or local, paracrine regulatory roles. In parallel, it will be relevant to address the regulation of VGF peptide expression and processing in pituitary endocrine cells, primarily by hypothalamic releasing/inhibiting hormones, as well as by several neurotropins and related factors.

\section{Acknowledgements}

G Boi, F Incollu and the Coalbe Company are thanked for tissue samples, National Institute of Diabetes and Digestive and Kidney Diseases, National Institute of Child Health and Human Development, the US Department of Agriculture and P Berger for the supply of antibodies. C B carried out the immunocytochemistry and in situ hybridization; GL F designed and supervised the study and developed VGF antisera in cooperation with P N, P C and G L C; $\mathrm{R} P$ ran the Western blots and G L F and C B wrote the paper. This work was supported by MIUR FIRB grants RBNE013 XSJ_002 and RBNE01 JKLF_002 to G L F, by grants RBNE013 XSJ_004 and RBNE01 JKLF_006 to R P, and by Ministry of Health Research grants.

\section{Funding}

The authors declare that there is no conflict of interest that would prejudice the impartiality of the present report. None of the supporting and funding bodies affected the writing of the present paper, nor its contents, in any way.

\section{References}

Alder J, Thakker-Varia S, Bangasser DA, Kuroiwa M, Plummer MR, Shors TJ \& Black IB 2003 Brain-derived neurotrophic factor-induced gene expression reveals novel actions of VGF in hippocampal synaptic plasticity. Journal of Neuroscience $\mathbf{2 3}$ 10800-10808.

Berger P, Staindl B \& Wick G 1988 Antigenic features of human protein hormones elucidated by monoclonal antibodies. In Strathclyde Bioengineering Seminars. The Influence of New Technology on Medical Practice, pp 212-219. Eds JP Paul, AB McCruden \& PW Schuetz. London: Macmillan Press.

Berger P, Klieber R, Panmoung W, Madersbacher S, Wolf H \& Wick G 1990 Monoclonal antibodies against the free subunits of human chorionic gonadotrophin. Journal of Endocrinology 125 301-309.

Canu N, Possenti R, Ricco AS, Rocchi M \& Levi A 1997 Cloning, structural organization analysis, and chromosomal assignment of the human gene for the neurosecretory protein VGF. Genomics $\mathbf{4 5}$ 443-446.

Cappai P, Cognie Y \& Branca A 1984 Use of the male effect to induce sexual activity in Sarda ewes. In The Male in Farm Animal Reproduction, pp 316-323. Ed M Courot. The Hague: Martinus Nijhoff Publishers.

Carcangiu V, Bini PP, Parmeggiani A, Floris B, Seren E \& Nuvoli P 1995 Effect of exogenous $\beta$-endorphin on blood level of PRL and $\mathrm{GH}$ in dry and lactating ewes. Archivio Veterinario Italiano 46 243-250.

Carrette O, Demalte I, Scherl A, Yalkinoglu O, Corthals G, Burkhard P, Hochstrasser DF \& Sanchez J-C 2003 A panel of cerebrospinal fluid potential biomarkers for the diagnosis of Alzheimer's disease. Proteomics 3 1486-1494.

Cocco C, Melis GV \& Ferri G-L 2003 Embedding media for cryomicrotomy: an applicative reappraisal. Applied Immunohistochemistry and Molecular Morphology 11 274-280.

Denef C \& van Bael A 1998 A new family of growth and differentiation factors derived from the N-terminal domain of proopiomelanocortin (N-POMC). Comparative Biochemistry and Physiology. Part C, Pharmacology, Toxicology and Endocrinology 119 317-324.

Ferri G-L, Levi A \& Possenti R 1992 A novel neuroendocrine gene product: selective VGF8a gene expression and immunolocalization of the VGF protein in endocrine and neuronal population. Molecular Brain Research 13 139-143.

Ferri G-L, Gaudio R-M, Cossu M, Rinaldi AM, Polak JM, Berger P \& Possenti R 1995 The 'VGF' protein in rat adenohypophysis: sex differences and changes during the estrous cycle and after gonadectomy. Endocrinology 136 2244-2251.

Graham ES, Webster CA, Hazlerigg DG \& Morgan PJ 2002 Evidence for the biosynthesis of a prolactin-releasing factor from the ovine pars tuberalis, which is distinct from thyrotropin-releasing hormone. Journal of Neuroendocrinology 14 945-954.

Gregory SJ, Townsend J, McNeilly AS \& Tortonese DJ 2004 Effects of prolactin on the luteinizing hormone response to gonadotropin-releasing hormone in primary pituitary cell cultures during the ovine annual reproductive cycle. Biology of Reproduction 70 1299-1305.

Hahm S, Mizuno TM, Wu TI, Wisor JP, Priest CA, Kozoc CA, Boozer CN, Peng B, McEvoy RC, Good P et al. 1999 Targeted deletion of the gene indicates that the encoded secretory peptide precursor plays a novel role in the regulation of energy balance. Neuron 23 537-548.

Hahm S, Fekete C, Mizuno TM, Windsor J, Yan H, Boozer CN, Lee C, Elmquist JK, Lechan RM, Mobbs CV et al. 2002 VGF is required for obesity induced by diet, gold thioglucose treatment, and Agouti and is differentially regulated in pro-opiomelanocortinand neuropeptide $\mathrm{Y}$-containing arcuate neurons in response to fasting. Journal of Neuroscience 22 6929-6938. 
Hassi J, Sikkila K, Ruokonen A \& Leppaluoto J 2001 The pituitary-thyroid axis in healthy men living under subartic climatological conditions. Journal of Endocrinology 169 195-203.

Levi A, Eldridge JD \& Paterson BM 1985 Molecular cloning of a gene sequence regulated by nerve growth factor. Science 229 393-395.

Lincoln GA, Andersson H \& Hazlerigg D 2003 Clock genes and the long-term regulation of prolactin secretion: evidence for a photoperiod/circannual timer in the pars tuberalis. Journal of Neuroendocrinology 15 390-397.

Liu JW, Andrews PC, Mershon JL, Yan C, Allen DL \& Ben-Jonathan N 1994 Peptide V: a VGF-derived neuropeptide purified from bovine posterior pituitary. Endocrinology 135 2742-2748.

McVicar CM, Cunningham RT, McClure N \& Curry WJ 2003 Chromogranin A proteolysis to generate beta-granin and WE-14 in the adenohypophysis during the rat oestrous cycle. Regulatory Peptides $1151-10$.

Manunta G \& Casu S 1968 On sexual activity in Sardinian strain sheep in different times of year. Zootecnia e Veterinaria 12 249-256.

Moorman AFM, Houweling AC, de Boer PAJ \& Christoffels VM 2001 Sensitive non radioactive detection of mRNA in tissue section: novel application of the whole-mount in situ hybridization protocol. Journal of Histochemistry and Cytochemistry 49 1-8.

Patterson JC \& Childs GV 1994 Nerve growth factor and its receptor in the anterior pituitary. Endocrinology 135 1689-1696.

Pelletier J 1973 Evidence for photoperiodic control of prolactin release in rams. Journal of Reproduction and Fertility 35 143-147.

Possenti R, Eldridge JD, Paterson BM, Grasso A \& Levi A 1989 A protein induced by NGF in PC12 cells is stored in secretory vesicles and released through the regulated pathway. EMBO Journal 8 2217-2223.

Possenti R, Rinaldi AM, Ferri G-L, Borboni P, Trani E \& Levi A 1999 Expression, processing, and secretion of the neuroendocrine VGF peptides by INS-1 cells. Endocrinology 140 3727-3735.

Ravault JP 1976 Prolactin in the ram: seasonal variation in the concentration of blood plasma from birth until three years old. Acta Endocrinologica 83 720-725.

Salton SRJ, Ferri GL, Hahm S, Snyder SE, Wilson AJ, Possenti R \& Levi A 2000 VGF: a novel role for this neuronal and neuroendocrine polypeptide in the regulation of energy balance. Frontiers of Neuroendocrinology 21 199-219.

Stark M, Danielsson O, Griffiths WJ, Jornvall H \& Johansson J 2001 Peptide repertoire of human cerebrospinal fluid: novel proteolytic fragments of neuroendocrine proteins. Journal of Chromatography. B, Biomedical Sciences and Applications 754 357-367.
Succu S, Cocco C, Mascia MS, Melis T, Melis MR, Possenti R, Levi A, Ferri GL \& Argiolas A 2004 proVGF-derived peptides induce penile erection in male rats: possible involvement of oxytocin. European Journal of Neuroscience 20 3035-3040.

Takumi I, Steiner DF, Sanno N, Teramoto A \& Osamura RY 1998 Localization of prohormone convertases $1 / 3$ and 2 in the human pituitary gland and pituitary adenomas: analysis by immunohistochemistry, immunoelectron microscopy, and laser scanning microscopy. Modern Pathology 11 232-238.

Thrun LA, Dahl GE, Evans NP \& Karsch FJ 1997 A critical period for thyroid hormone action on seasonal changes in reproductive neuroendocrine function in the ewe. Endocrinology 138 3402-3409.

Tortonese DJ, Brooks J, Ingleton PM \& McNeilly AS 1998 Detection of prolactin receptor gene expression in the sheep pituitary gland and visualization of the specific translation of the signal in gonadotrophs. Endocrinology 139 5215-5223.

Trani E, Ciotti MT, Rinaldi AM, Canu N, Ferri GL, Levi A \& Possenti R 1995 Tissue-specific processing of neuroendocrine protein VGF. Journal of Neurochemistry 65 2441-2449.

Trani E, Giorgi A, Canu N, Amadoro G, Rinaldi AM, Halban PA, Ferri G-L, Possenti R, Schinina ME \& Levi A 2002 Isolation and characterization of VGF peptides in rat brain. Role of PC1/3 and PC2 in the maturation of VGF precursor. Journal of Neurochemistry 81 565-574.

Uehara M, Yaoi Y, Suzuki M, Takata K \& Tanaka S 2001 Differential localization of prohormone convertases PC1 and PC2 in two distinct types of secretory granules in rat pituitary gonadotrophs. Cell and Tissue Research 304 43-49.

Van den Pol AN, Decavel C, Levi A \& Paterson B 1989 Hypothalamic expression of a novel gene product, VGF: immunocytochemical analysis. Journal of Neuroscience 9 4122-4137.

Van den Pol AN, Bina K, Decavel C \& Ghosp P 1994 VGF expression in the brain. Journal of Comparative Neurology 347 455-469.

Wisor JP \& Takahashi JS 1997 Regulation of the VGF gene in the golden hamster suprachiasmatic nucleus by light and by the circadian clock. Journal of Comparative Neurology 378 229-238.

Received in final form 24 March 2005

Accepted 8 April 2005

Made available online as an Accepted Preprint 26 April 2005 